\title{
La diplomacia del anticomunismo: la influencia del gobierno de Getúlio Vargas en la interrupción de las relaciones diplomáticas de Uruguay con la URSS en diciembre de 1935
}

\author{
ANA MARÍA RODRÍGUEZ AYÇAGUER*
}

\begin{abstract}
Resumo: Quando aconteceram os levantes da ANL, em novembro de 1935, o regime de Vargas afirmou que os revolucionários contavam com o apoio da Legação soviética em Montevidéu. Embora o Itamaraty não pôde provar essa intromissão, o governo de Terra rompeu relações com a URSS, demonstrando a efetividade das pressões exercidas pela "diplomacia do anticomunismo", bem como o caráter prioritário que tinha para o pequeno Uruguai a amizade com seu poderoso visión, o Brasil.
\end{abstract}

Abstract: On November 1935, when the ANL revolutionary movements took place, the Vargas regime argued that revolutionaries had been helped by the Soviet Union Legation in Montevideo. Although Itamaraty could not prove that such intervention had taken place, Terra's government severed diplomatic relations between Uruguay and the Soviet Union, demonstrating not only the effectiveness of "anticommunism diplomacy", but the importance assigned by the small Uruguay to the friendship of the powerful neighbor Brazil.

Palavras-chave: Diplomacia. Anticomunismo. Revolução.

Key words: Diplomacy. Anticommunism. Revolution.

\section{Introducción}

El 27 de diciembre de 1935 el gobierno uruguayo encabezado por Gabriel Terra declaró interrumpidas las relaciones diplomáticas con la Unión Soviética. El correspondiente decreto aludía a la exposición presentada a la Cancillería uruguaya por la Embajada

* Departamento de Historia del Uruguay, Facultad de Humanidades y Ciencias de la Educación, Universidad de la República, Montevideo, Uruguay. E-mail: amra@adinet.com.uy 
del Brasil, en la que se relataban los sucesos revolucionarios ocurridos en ese país en el mes de noviembre de ese año, afirmándose que se trataba de una sublevación netamente comunista, inspirada en los propósitos manifestados en las reuniones del VII Congreso de la Internacional, reunido en Moscú a mediados del mismo año, y que en dicha nota se aseveraba "de terminante manera, que el Gobierno soviético instigaba y prestaba su concurso a los elementos comunistas del vecino Estado por intermedio de la Legación soviética cerca de nuestro Gobierno". El decreto señalaba que "las afirmaciones del Gobierno del Brasil, dadas bajo la fe de sus palabras", se hallaban fortalecidas por la información de que disponía el gobierno uruguayo, entre las que se destacaban además de las ya aludidas actuaciones del Congreso de Moscú, el hecho de que "la Legación Soviética en Montevideo ha girado en cheques al portador gruesas sumas, cuyos destinos no pueden determinarse pero pueden fundar una presunción seria que concordaría con la aseveración atribuida a este respecto por el Gobierno del Brasil". Luego de fundamentar que no podía establecerse separación entre la III Internacional y el Gobierno de los Soviets, las autoridades uruguayas concluían que había "suficiente motivo para suprimir una de las causas de inquietud que preocupan al país amigo, que está convencido que la Legación Soviética en Montevideo es centro de acción del comunismo que acaba de tener tan sangrientas manifestaciones en su seno", por lo que, reafirmando las manifestaciones de colaboración y buena voluntad hechas al gobierno del país vecino luego de estallada la revolución, se adoptaba la resolución la señalada. ${ }^{1}$

El texto del decreto estaba cuidadosamente redactado. Las afirmaciones del Gobierno del Brasil aparecen como "dadas bajo la fe de sus palabras", y el hincapié parece estar, más que en los hechos probados, en el "convencimiento" de las autoridades del país vecino de la ingerencia de la Legación soviética en Montevideo en los hechos de referencia. Todo ello proporciona fuertes indicios de que la decisión del gobierno uruguayo fue adoptada sin pruebas fehacientes y bajo fuerte presión del país vecino.

En la historiografía uruguaya el tema fue abordado por Raúl Jacob y Juan Oddone, y si bien ambos insinuaron la existencia de posibles presiones del régimen de Vargas, también coincidieron en

1 Registro Nacional de Leyes y Decretos, 1935, p. 934-937. El decreto estaba firmado por Terra y todos sus Ministros. 
situar dicha decisión en el marco de un viraje conservador protagonizado por la política exterior uruguaya durante el terrismo - no ajeno a la propia orientación ideológica del Presidente Terra y sus principales colaboradores - que ejemplifican, además, por la ruptura de relaciones con la República Española y el temprano reconocimiento de la Junta de Burgos, así como un notorio acercamiento a la Italia Fascista y la Alemania nazi. ${ }^{2}$

La interrupción de las relaciones diplomáticas de Uruguay con la URSS reviste particular interés por haber sido Uruguay el primer país en América del Sur en haber concedido el reconocimiento de jure del régimen soviético (1926), y porque fue el propio gobierno de Terra el que en 1933 decidió la reanudación de las relaciones diplomáticas con la URSS.

¿Por qué, entonces, a tan solo un año de que Uruguay abriese su Legación en Moscú, se adoptó aquella decisión? ¿Hubo presión del gobierno de Vargas? ¿Eran ciertas las acusaciones sobre la conexión uruguaya del levantamiento comunista? ¿Cuáles fueron los elementos realmente determinantes para adoptar aquella resolución?

2 JACOB, Raúl. El Uruguay de Terra. 1931-1938. Montevideo: Ed. Banda Oriental, 1983, p. 114-115; y ODDONE, Juan. Uruguay entre la Depresión y la Guerra. 1929-1945. Montevideo: Fundación de Cultura Universitaria-Facultad de Humanidades y Ciencias, 1990, p. 160-163. Los historiadores que han estudiado el período de Vargas y, concretamente, la revolución de la Alianza Nacional Libertadora y su contexto, hasta donde sabemos no han dedicado particular atención al tema de la ruptura de relaciones por parte de Uruguay. Y cuando lo mencionan, como es el caso de Robert Levine, dicha decisión no es atribuida a presiones por parte de Brasil, sino a una reacción del gobierno uruguayo ante el hecho de que el Komintern hubiese utilizado a Montevideo como base para sus actividades en América del Sur. Levine basa su afirmación en información tomada de las memorias de un militante comunista brasileño (Hónorio de Freitas Guimarães, alias "M"), escritas en la cárcel (LEVINE, Robert. The Vargas Regime: the critical years. 1934-1938. New Cork: Columbia University Press, 1970, p. 187). El interés se ha centrado, más bien, en el origen de los fondos utilizados por los revolucionarios. Al respecto señala Ricardo A. Silva Seitenfus: "O financiamento dessa operação ainda hoje continua um enigma. Segundo certas fontes diplomáticas brasileiras e americanas retomadas por DULLES, J. W. F., 'Anarquistas..., op. cit., p. 430, nota 52, é Moscou que fornece 100.000 dólares destinados a 'analisar o grau de fertilidades do solo sul-americano para uma insurreição'. Em compensação, os comunistas brasileiros, e em particular a irmã de Luis Carlos Prestes, afirmam que o dinheiro provém da quantia entregue em 1930 pela AL para a compra de armas na Argentina. Cf. Ibidem, p. 430" (SEITENFUS, R. A. S. O Brasil de Getúlio Vargas e a formacão dos blocos: 1930-1942. O Processo do envolvimento brsileiro na II Guerra Mundial. São Paulo, Ed. Nacional, 1985, p. 49, nota 83). En su biografía de Getúlio Vargas, J. W. F. Dulles, refiriéndose al mismo tema, señala: "Prestes had most of the money which Aranha had given him en 1930; also a transfer of $\$ 100.000$ which the Russian Communists sent from Moscow via New York to Montevideo for use in Brazil and Argentina 'on an experimental basis'" , y menciona como fuente de dicha información "Carlos da Costa Leite and Meireles family, interview, September 6, 1963" (DULLES, J. W. F. Vargas of Brasil. A political Biography. Austin \& London: University of Texas Press, 1967, p. 148). 
Cabe advertir, sin embargo, que nuestro interés se centra, no tanto en establecer la veracidad de aquellas acusaciones, sino en determinar cuáles fueron los elementos de juicio de que dispuso el gobierno uruguayo en el momento de tomar la decisión.

El presente artículo pretende arrojar alguna luz sobre estas interrogantes, llamando la atención sobre lo que hemos dado en llamar - con cierto atrevimiento - "diplomacia del anticomunismo", englobando bajo esta denominación la postura crítica sobre la "permisiva" actitud del gobierno uruguayo ante las actividades de los militantes comunistas y los agentes "bolcheviques", posición documentada abundantemente en la correspondencia diplomática generada desde y hacia las representaciones diplomáticas en Uruguay de varios países, fundamentalmente Estados Unidos, Gran Bretaña y, como veremos, también Brasil.

El trabajo se nutre, fundamentalmente, del relevamiento de fuentes primarias pertenecientes al Archivo Histórico Diplomático del Ministerio de Relaciones Exteriores de Uruguay, y de las provenientes del Archivo Histórico do Itamaraty. ${ }^{3}$ Hemos utilizado asimismo documentación de los National Archives (Washington, DC), correspondientes a los archivos del Departamento de Estado.

\section{Las relaciones de Uruguay con la Unión Soviética (1917-1934)}

Las relaciones entre Uruguay y Rusia se iniciaron en 1857 y en 1906, durante la primera presidencia de José Batlle y Ordóñez, Uruguay abrió su Legación en Moscú. En 1917, producida la conmoción revolucionaria, el gobierno soviético retiró sus poderes a todos los representantes de Rusia en el exterior y en noviembre de ese año revocó su representación a todos los diplomáticos extranjeros que habían sido acreditados ante el gobierno zarista. En ese momento Uruguay dejó, de facto, de mantener relaciones diplomáticas con la URSS; no hubo ruptura formal sino que se produjo una discontinuidad. ${ }^{4}$

Luego de la paz que firmara por separado el país de los soviets con Alemania, las potencias occidentales no reconocieron al ré-

3 Los documentos provenientes del Archivo Histórico do Itamaraty fueron relevados por nuestro colega Alex Borucki, cuya generosidad agradezco en forma muy especial.

4 GROS ESPIELL, Héctor. Las relaciones diplomáticas entre el Uruguay y Rusia. Algunos puntos de interés histórico y jurídico. En: Temas Internacionales. Montevideo: Melibea Ediciones, 2001, p. 261-274. 
gimen soviético, apelaron a la intervención armada para derrotarlo y luego al llamado "cordón sanitario" destinado a impedir el contagio de la experiencia revolucionaria al resto de Occidente. Sin embargo, el fracaso de ambas estrategias haría que, a partir de 1921 esa actitud comenzara a cambiar: ese año Inglaterra firmó un acuerdo comercial que significó el reconocimiento de hecho del gobierno soviético. En 1924, Alemania, Inglaterra y Francia le otorgaron el reconocimiento de jure, y el primero de estos países estableció relaciones diplomáticas. ${ }^{5}$ Ese año se instaló en Nueva York la Compañía Comercial soviética AMTORG, que desarrolló una intensa actividad de promoción del intercambio comercial entre ambos países, sentando las bases económicas que fundamentarían el inicio de relaciones diplomáticas decidido por el presidente Franklin D. Roosevelt en noviembre de $1933 .^{6}$

En noviembre de 1925 la Amtorg S.A. abrió una sucursal en Buenos Aires y desde allí, uno de sus funcionarios principales, Boris Kraevsky, cruzaría a Montevideo en varias oportunidades, realizando contactos comerciales y políticos. En agosto de 1926 Uruguay reconoció de jure a la URSS, reanudando sus relaciones diplomáticas interrumpidas en 1917. No hubo en ese momento, sin embargo, intercambio de misiones diplomáticas.

La "peligrosa" conmixtión entre las tareas comerciales y las políticas y de propaganda presuntamente llevadas a cabo por los funcionarios comerciales soviéticos, era motivo de preocupación de las autoridades norteamericanas. ${ }^{7}$ Los funcionarios del servicio exterior de ese país reportaban regularmente sobre las actividades "bolcheviques" y comunistas en sus lugares de destino, ofreciéndonos un temprano ejemplo de la "diplomacia del anticomunismo". 8 Pero también los informes diplomáticos británicos

5 Ibid, p. 265.

6 Hasta 1933 el gobierno estadounidense se mantuvo en una cerrada negativa a reconocer el régimen soviético - debido al rechazo de éste a cumplir con las obligaciones financieras contraídas por los anteriores gobiernos de aquel país. No obstante, como ha demostrado Katherine Siegel, ésto no fue óbice para que se desarrollaran vinculaciones comerciales y financieras. Entre 1923 y 1930 las exportaciones de Estados Unidos a la Unión Soviética se multiplicaron por veinte, suministrando aquel país más de la cuarta parte de las importaciones soviéticas (SIEGEL, Katherine A. S. Loans and legitimacy: the evolution of Soviet-American Relations, 1919-1933. Lexington: The University Press of Kentucky, 1996, Capítulos $1,6$ y 8$)$.

7 SIEGEL, ob. cit., p. 87-88.

8 Cabe señalar que, según un especialista en la historia de las relaciones exteriores de Estados Unidos, el temor a la revolución ha sido uno de las líneas de larga duración en la política exterior de ese país (cfr: HUNT, Michael H. Ideology and U.S. Foreign Policy. New Haven, 1987). 
registraban cuidadosamente las actividades comunistas y soviéticas en el Uruguay. ${ }^{9}$

En agosto de 1926, el Ministro de Estados Unidos en Uruguay advirtió que Montevideo, que ya era desde tiempo atrás "un centro para la propaganda comunista", ahora con el reconocimiento otorgado a la URSS se transformaría "en el centro oficial para la propaganda comunista en esta parte del mundo" ${ }^{10}$

Esa preocupación se vería reforzada en 1928, luego de que la Legación estadounidense en Buenos Aires informara de la creación de una nueva compañía soviética, la Iuyamtorg S.A. que pronto abriría una sucursal en Montevideo. El Departamento de Estado instruyó a los funcionarios del servicio exterior en América del Sur para que enviasen toda la información a su alcance sobre las actividades de dicha compañía. "...Llamamos su atención - se decía en dicha comunicación - sobre el hecho de que es costumbre de los representantes soviéticos, teóricamente designados para promover el intercambio comercial, el desarrollar actividades políticas [...], en líneas generales, cualquier novedad en el terreno de las relaciones comerciales o políticas entre los países sudamericanos y la Rusia soviética, debería ser rápidamente informada al Departamento". ${ }^{11}$

Es de destacar, fundamentalmente, la entrada de los soviéticos en el mercado de los combustibles ya que, si bien los volúmenes comercializados no podían compararse con las ventas de las compañías anglo-estadounidenses que dominaban el mercado, su presencia alentó las posturas nacionalistas de sectores que vieron en las importaciones de combustibles soviéticos un elemento para contrarrestar la fuerte dependencia de los trusts petroleros, y una garantía ante las posibles represalias con que las compañías petroleras pudieran eventualmente castigar la creación de emprendimientos petroleros estatales. ${ }^{12}$

Es interesante señalar la continuidad que existió en el señalamiento realizado en la correspondencia diplomática estadounidense, de la falta de conciencia de las autoridades uruguayas

9 Cfr: NAHUM, Benjamín. Informes diplomáticos de los representantes del Reino Unido en el Uruguay, Tomos III a VII (1921-1937). Montevideo: Departamento de Publicaciones de la Universidad de la República, 1993, 1994, 1996 y 1997.

10 U. Grant-Smith al Secretario de Estado, Montevideo, 24 de agosto de 1926. National Archives (Washington), Record Group 59, No 833.00B/4 [en adelante: NA,RG59].

11 NA, RG59, No 810.00B/Iuzhamntorg/1.

12 Sobre las actividades de la Iuyamtorg en Uruguay y su participación en el mercado de los combustibles, cfr: JACOB, Raúl. Inversiones extranjeras y petróleo: la crisis de 1929 en Uruguay. Montevideo: F.C.U., 1979. 
sobre los peligros que encerraban las actividades comunistas y/o "bolcheviques", reclamo que fue un leit-motiv de la "diplomacia del anticomunismo". Téngase presente que el Partido Comunista uruguayo, creado en 1921, actuaba dentro de la legalidad y tenía representación parlamentaria. A ello debe agregarse no solo el hecho de que las autoridades uruguayas habían decidido el reconocimiento de la URSS - Uruguay fue, luego de México, el segundo país de América Latina en hacerlo - sino que figuras de primer nivel del partido batllista (en ese entonces, sector mayoritario dentro del gobernante Partido Colorado), como Baltasar Brum y Domingo Arena, habían aceptado actuar como asesores legales de la compañía soviética Iuyamtorg en el medio local. ${ }^{13}$

Resulta sugestiva esta vinculación de los líderes batllistas a la compañía soviética, poco antes de que dicho movimiento político promoviera el primer proyecto de refinería con participación estatal, que fuera presentado al Consejo Nacional de Administración, en agosto de 1929.14 La iniciativa había sido elaborada con el asesoramiento del Director de Yacimientos Petrolíferos Fiscales de Argentina, Gral. Enrique Mosconi, que por ese entonces mantenía un duro enfrentamiento con los intereses petroleros extranjeros. ${ }^{15}$ El ente petrolero uruguayo - la Administración Nacional de Combustibles, Alcohol y Pórtland, A.N.C.A.P. - recién sería creado en octubre de 1931. Cuando el flamante ente estatal llamó a licitación para la provisión de combustibles refinados, las compañías

13 Tel. confidencial de Grant-Smith al Secretario de Estado, Montevideo, 21 de diciembre de 1927 (NA, RG59, N 833.00B). Domingo Arena, político de larga trayectoria en el batllismo, era la mano derecha de José Batlle y Ordóñez y, sin lugar a dudas, su correligionario y amigo más cercano. Baltasar Brum, figura destacadísima de ese sector político, había sido parlamentario, Canciller y Presidente de la República (1919-1923).

14 La Constitución de 1918 - que rigió el ordenamiento institucional uruguayo desde el $1^{\circ}$ de marzo de 1919 hasta el golpe de estado liderado por el Presidente Gabriel Terra el 31 de marzo de 1933 - instauró un Poder Ejecutivo dual, constituido por un Presidente de la República (del que dependían los Ministerios de Interior; Guerra y Marina; y Relaciones Exteriores) y un organismo colegiado de nueve miembros, el Consejo Nacional de Administración, del que dependían las carteras que orientaban la política económica (Industrias y Hacienda).

15 Como es bien conocido, el gobierno de Hipólito Irigoyen había firmado un contrato con la Iuyamtorg para aprovisionamiento de petróleo, que contemplaba el pago del mismo con productos argentinos. Dicho contrato fue dejado sin efecto luego del golpe de estado del 6 de setiembre de 1930 en ese país. Sobre la presencia de los soviéticos en el mercado de combustibles argentino, véase: SOLBERG, Carl E. Petróleo y nacionalismo en la Argentina. Buenos Aires: Emecé, 1982; y GARCÍA MOLINA, F.; MAYO, C. y ANDINO, O., La diplomacia del petróleo (1916-1930). Buenos Aires: Centro Editor de América Latina, 1983. 
petroleras extranjeras, en un claro intento de boicotear su funcionamiento, no se presentaron a dicha convocatoria. Sí lo hizo la Iuyamtorg y así fue como ANCAP comenzó a funcionar, distribuyendo combustibles soviéticos, provocando la hostilidad de las compañías petroleras extranjeras. ${ }^{16}$

En el entorno de 1930-1932 se produce un verdadero estallido de la "diplomacia del anticomunismo". Los informes diplomáticos estadounidenses y británicos correspondientes a ese período denunciaron reiteradamente la permisividad de las autoridades uruguayas frente al accionar comunista, sindicando a Montevideo como una "pequeña Moscú" y "cuartel general" de las actividades de la Internacional Comunista en América del Sur. Por cierto que mucho de verdad había en todo ésto. El Secretariado Sudamericano de la Internacional Comunista había funcionado en Buenos Aires desde 1928 pero, al producirse el golpe del 6 de setiembre de 1930 y la represión de que fueron objeto las organizaciones y partidos de izquierda, hizo que dicho organismo trasladase su accionar a Montevideo. No obstante, antes de 1930 pasaron por la capital uruguaya muchos de los cuadros de la Internacional Comunista destinados a América Latina, gracias a las facilidades para moverse que allí existían. Sobre ello hay múltiples referencias, no solo en las denuncias de que se hacían eco los referidos informes diplomáticos, sino en los testimonio de algunos de sus más destacados militantes de la época. ${ }^{17}$

16 Al respecto, véase: RODRÍGUEZ AYÇAGUER, Ana María. Las compañías petroleras extranjeras frente a A.N.C.A.P.: de la incredulidad al hostigamiento (1931-1932). En: Primeras Jornadas de Historia Económica, A.U.D.H.E., Montevideo, 1995; y JACOB, Inversiones extranjeras y petróleo, cit.

17 El dirigente comunista argentino Luis Sommi (1906-1983), que a comienzos de la década de 1930 había vivido en Moscú como funcionario de la Internacional (había sido compañero de Olga Benario antes de que ésta partiese junto a Prestes hacia Brasil, y fue el último delegado del P. Comunista Argentino ante la Internacional Comunista), declaró en reportaje que se le hiciera en México en 1982: "El Buró Sudamericano de la Internacional que se había instalado en Buenos Aires en 1928 y funcionaba legalmente, con la chapa en la puerta que decía 'Secretariado Sudamericano de la IC', se trasladó a Montevideo después de la caída de Irigoyen. (...). A mediados de 1932 volví a Moscú y también en el 33. También estuve en Argentina, Brasil y Uruguay hasta fines de 1934" (citado en: "El último delegado ante el Kremlin", Clarín, Buenos Aires, 31 de agosto de 1997, Segunda Sección, p. 7). Véase también: GILBERT, Isidoro. El oro de Moscú. Historia secreta de la diplomacia, el comercio y la Inteligencia soviética en la Argentina. Buenos Aires, Planeta, 1994; y DUJOVNE, Alicia. El camarada Carlos. Itinerario de un enviado secreto. Buenos Aires: Aguilar, 2007. En esta última obra (p. 234) se cita una carta enviada a su esposa desde Montevideo, el 13 de mayo de 1929, por un destacado cuadro de la Internacional, el suizo Jules Humbert-Droz, en la que éste se refería a la capital uruguaya en estos términos: "Es una pequeña ciudad provinciana, un poco como Lyon, bastante muerta y tranquila. Desde el punto de vista policial, esto es de una seguridad desconcertante. Cada uno entra y sale como quiere sin presentar papeles y dando el nombre que quiera. Una vez adentro ya no hay control. Es un verdadero paraíso para los 'comerciantes de nuestra especie'"'. 
Es en ese momento que recrudecen las denuncias sobre posibles atentados y movimientos revolucionarios. La prensa conservadora uruguaya se hizo eco de las mismas y todo ello se inscribió en el marco de un áspero debate entre el reformismo batllista y los sectores conservadores de ambos partidos tradicionales, dispuestos a frenar algunas de sus propuestas reformistas más irritantes. El Presidente Terra, electo en noviembre de 1930 como candidato del batllismo, se fue distanciando de dicho movimiento, transformándose en el hombre de confianza de los sectores conservadores. En el marco de esta construcción de una imagen de hombre razonable - alejado de las "utopías" y el "avancismo" que caracterizaban a algunos de los principales dirigentes del batllismo - y de "hombre fuerte", en febrero de 1932 Terra denunció el peligro de un supuesto "complot" comunista próximo a estallar y promovió una represión contra las actividades de partidos y organizaciones de izquierda. ${ }^{18}$ Las medidas adoptadas durante la llamada "crisis comunista" de febrero, fueron sin embargo transitorias y no se llegó a la ilegalización del Partido Comunista, medida difícilmente aceptable para el sistema político uruguayo. ${ }^{19}$

En marzo de 1933 la crisis política desembocó en la ruptura institucional. El Presidente Gabriel Terra disolvió el parlamento y el Consejo Nacional de Administración. El movimiento contó con el apoyo de los sectores conservadores dentro del Partido Colorado y del sector mayoritario del Partido Nacional. También recibió el entusiasta apoyo de los intereses extranjeros y de las legaciones de Gran Bretaña y Estados Unidos.

Entre los partidarios de la "Revolución de Marzo" - como se autodenominó el régimen - abundaban los simpatizantes del fascismo, entre los que se contaba el propio Terra, cuyas excelentes relaciones con el representante diplomático de la Italia fascista, Serafino Mazzolini, eran continuamente denunciadas por la prensa opositora y referidas con preocupación en los informes diplomáticos británicos y estadounidenses.

18 Un análisis del proceso político uruguayo en este período, así como de la referida "crisis comunista", en: CAETANO, Gerardo y JACOB, Raúl. El nacimiento del terrismo. Vol. 2: Camino al golpe (1932). Montevideo: Ed. Banda Oriental, 1990.

19 Un proyecto de ley en ese sentido, presentado en 1937 por el diputado Bernardo Kayel, no fue aprobada. El Partido Comunista uruguayo actuó en la legalidad, ininterrumpidamente, desde su fundación en 1921 hasta la ilegalización y disolución de los partidos y movimientos de izquierda dispuesta por la dictadura civil-militar en noviembre de 1973. 
En este marco político-ideológico puede resultar sorprendente la decisión del Presidente Terra de abrir la Legación de Uruguay en Moscú, adoptada a mediados de $1933 .{ }^{20}$ No parece haber ninguna duda en cuanto al pragmático designio perseguido por esta iniciativa: la apertura de nuevos mercados a las exportaciones uruguayas, en el marco de las dificultades determinadas por la gran depresión. Después de todo, Estados Unidos acababa de tomar idéntica medida con similares fundamentos. En Uruguay, los productores rurales, que contaban con renovado peso en la constelación de poder (su gremial más combativa, la Federación Rural del Uruguay, había estado en la vanguardia de la ofensiva conservadora contra el régimen depuesto) no oponían reparos a comerciar con los comunistas; solo los preocupaba vender la carne, los cueros y la lana...

El Presidente Terra designó al General Eduardo Da Costa como Enviado Extraordinario y Ministro Plenipotenciario en Moscú. Sus cartas credenciales, fechadas el 6 de noviembre de 1933, fueron presentadas al Presidente Kalinin el 10 de marzo de 1934. Ese mismo día, el representante soviético, Alexander Minkin - hasta ese momento principal jerarca de la Iuyamtorg en Montevideo presentó sus credenciales a Terra. ${ }^{21}$

\section{Uruguay, Brasil y la diplomacia del anticomunismo: antecedentes}

La agenda bilateral en 1935: la primacía de lo político. En 1935 los temas de la agenda bilateral de Brasil con Uruguay estuvieron completamente dominados por lo político. En efecto, los asuntos que concentraron el accionar de ambas Cancillerías fueron cinco, a saber: $1^{\circ}$ ) La llamada "Revolución de Paso Morlán", en el mes de enero, fracasado levantamiento opositor contra el régimen de Terra, durante la cual se suceden los apremiantes pedidos de las autoridades uruguayas para que el gobierno brasileño impida el pasaje de hombres y armas hacia territorio uruguayo, y arreste e interne a los revolucionarios que pasan la frontera. Un duro recordatorio de la absoluta necesidad del gobierno uruguayo de

20 En 1929 se iniciaron negociaciones informales para proceder en ese sentido, tratativas que se oficializaron en 1931 y culminaron, en agosto de 1933. Fue entonces que el Canciller Alberto Mañé comunicó oficialmente al Comisario del Pueblo de Relaciones Exteriores de la Unión Soviética, que el gobierno uruguayo había decidido establecer una representación diplomática permanente en Moscú. (GROS ESPIELL, ob. cit., p. 26-267).

21 Ibid., p. 267. 
contar con la buena voluntad y la colaboración del gobierno de Brasil. $2^{\circ}$ ) Los trabajos de demarcación de la frontera seca entre ambos países, iniciados en 1916 y finalizados en 1935, lo que motiva un intercambio de congratulaciones entre el Canciller Macedo Soares y el Embajador Bueno, ya que los resultados han contemplado enteramente los deseos de Itamaraty. $3^{\circ}$ ) La visita del Presidente Getúlio Vargas a Uruguay, entre fines de mayo y principios de junio, provoca un nutrido flujo de correspondencia sobre los preparativos y el programa de la visita, a la que Uruguay otorga gran importancia. Es el momento de demostrar al ilustre huésped la simpatía hacia su persona y su pueblo, así como la sintonía con su proyecto político. En medio de desfiles, banquetes y discursos, se entablaron seguramente contactos entre los elencos civiles y militares de ambos gobiernos, que resultarán muy útiles cuando lleguen los sucesos de noviembre. $4^{\circ}$ ) La posición de Brasil en relación con la invitación de Argentina y Chile para participar en la Comisión Neutral de paz en la Guerra del Chaco - Brasil se negó a participar en la Comisión si Uruguay (y Estados Unidos) no formaban parte de la misma - provocó una natural corriente de simpatía hacia el Presidente Vargas en el Uruguay. Una vez más el gobierno uruguayo había visto reafirmada su necesidad de contar con el favor del gobierno del Brasil y éste, a su vez, le había dado muestras de "sincera amistad", lo que reforzó las simpatías del Presidente Terra y de su gobierno por el régimen de Vargas. $5^{\circ}$ ) El tema de las actividades "subversivas" - comunistas o anarquistas - ya estuvo presente en la correspondencia diplomática de ambos países en los meses previos al levantamiento de noviembre en Brasil. La primera vez que ésto ocurrió, lo hizo bajo la forma de una advertencia del Embajador de Brasil a su Canciller: según "informaçoes fidedignas", decía Lucillo Bueno, podrían producirse movimientos comunistas en las capitales de varios países de América, entre ellas Río, en los días 18 de marzo, aniversario de la proclamación de la Comuna de París, y 21 del mismo mes, aniversario de la República de los Soviets en Hungría. ${ }^{22}$ Cuatro días más tarde - ignoramos si motivado por la referida advertencia Itamaraty solicitó a Bueno que informara con urgencia si en

22 Tel. Confidencial N ${ }^{\circ} 6$ de Bueno a Macedo Soares, Montevideo, 11 de marzo de 1935. Archivo Histórico do Itamaraty, Telegramas Montevideo-Río de Janeiro, 1935-1936. En adelante: AHI, Vol. 3 (la documentación está encuadernada en volúmenes; le hemos asignado un número a cada uno de los volúmenes consultados a efectos de abreviar la cita). 
Uruguay era conocido "Simonrad Dowytzky, indigitado como delegado directo de Moscou". El texto del cable no hablaba muy bien de los servicios de inteligencia brasileños: se trataba, obviamente, de Simón Radowitzky, quien lejos de ser un "delegado directo de Moscú", era un conocido militante anarquista. La policía uruguaya tampoco pareció estar a la altura de las circunstancias: contestó que ese individuo "nao tem antecedentes e nem é conhecido nesta cidade", según transmitió Bueno. Pero días más tarde Bueno envió una rectificación: "Tratase do concedido anarchista Simonrad Dowytzky [sic]. Esse individuo está, ha quatro mezes, confinado na ilha das Flores, incommunicavel. Foi o que assassinou, ha annos, o Chefe de Policia de Buenos Airse, Coronel Falcon, tendo sido indultado pelo Presidente Irigoyen e deportado para Montevidéo, quando se permittia ser, este paiz, refugio dos peores elementos. Segundo me informou, pessoalmente, o Chefe de Policia, esse anarchista foi detido, aquí, logo após o seu regresso do Brasil, onde esteve algum tempo, segundo parece, con nome supposto". ${ }^{23}$

La alusión a un tiempo pasado, en el que Montevideo se había "permitido" ser "refugio de los peores elementos", muestra la recepción lisa y llana de las acusaciones contra Uruguay que habían estado presentes en esa "diplomacia del anticomunismo". Refleja asimismo, la asunción por parte del Embajador Bueno de que aquello no sucedía más, como consecuencia - cabe suponer - del advenimiento de la "Revolución de Marzo". Sin embargo, pocos meses después el Embajador Bueno tornaba aquel pasado en presente, al afirmar que el Presidente Terra no creía en el peligro que podía significar el comunismo para estos países. La afirmación había sido formulada en un cable fechado el 13 de julio, en el que Bueno solicitaba a Itamaraty información sobre el descubrimiento de una organización comunista vinculada a Moscú, que tendría ramificaciones en Uruguay, hecho del que había tenido conocimiento por la prensa. Pedía se le enviase el informe del Jefe de Policía de Río a fin de ofrecérselo al Gobierno uruguayo ya que "Infelizmente, o Presidente Terra, a pesar de meus muitos avisos,

23 Tel. No 39, Confidencial, de Macedo Soares a Bueno, Río, 15 de marzo de 1935 (AHI, Telegramas Río-Montevideo, 1935-1936. En adelante: AHI, Vol. 6; Tel. N ${ }^{\circ} 73$, Confidencial, de Bueno a Macedo Soares, Montevideo, 26 de marzo de 1935 (AHI, Vol. 3); y Tel. $\mathrm{N}^{\mathrm{o}} 75$, Confidencial, de Bueno a Macedo Soares, Montevideo, $1^{\circ}$ de abril de 1935 (ibid.). 
nao crê na existencia de comunismo no Brasil e nos paizes do Rio da Prata". ${ }^{24}$ Como respuesta Bueno recibió un recorte del diario Correio da Manhâ del 12 de julio, en el que aparecía la entrevista realizada al Jefe de Policía de Río de Janeiro, Flinto Müller. ${ }^{25}$ En dicha nota, titulada "A implantaçao e irradiaçao do extremismo no Brasil", Uruguay aparecía mencionado junto a Argentina y Brasil como escenarios de futuras revoluciones político sociales precedidas por "neo-movimientos" nacionalistas. No había en aquellas declaraciones referencia alguna a que las actividades comunistas mencionadas fuesen promovidas o dirigidas desde Montevideo.

Dos semanas más tarde, nuevas informaciones periodísticas provenientes de Brasil ya aludían concretamente a la participación de la Legación soviética en Montevideo en actividades de tipo subversivo El 5 de agosto el Embajador Bueno telegrafió a Macedo Soares que, "para informar a este Governo, que não cre no perigo comunista", le rogaba le enviase información sobre lo sucedido en relación con la Sociedad Rusa Ucraniana de Porto Alegre la que, según informaba la prensa, había sido cerrada por sus actividades subversivas, habiéndose constatado en las investigaciones realizadas por la policía que dicha Sociedad "estava em relação direta com a Legação Sovietica em Montevideo da qual recebia e pedia instrucções militares" ${ }^{26}$

En dicho cable están presentes dos elementos que serán una constante en la correspondencia de la Embajada brasileña en Montevideo durante la crisis diplomática que nos ocupa: el tono crítico hacia la postura de Terra, por no reconocer el peligro que suponen las actividades comunistas en su país, y la actitud "misional" del Embajador Bueno, determinado a convencer al primer mandatario de su error. Esta postura era fruto, como veremos, tanto de las instrucciones recibidas de su gobierno, como de sus firmes convicciones personales.

Mientras tanto, la Cancillería uruguaya comenzaba a procesar la información que estaba recibiendo sobre esta temática, desde

24 Tel. N ${ }^{\circ}$ 183, Reservado, de Bueno a Macedo Soares, Montevideo, 13 de julio de 1935. (AHI, Vol. 3).

25 Mario de Pimentel Brandão (por el Ministro de Estado) a Bueno. Nota NP/50/500.1, Río, 20 de julio de 1935 (AHI, Despachos Río-Montevideo. En adelante. AHI, Vol. 1). El referido recorte fue entregado por Bueno al gobierno uruguayo. Dicha campaña periodística estaba vinclada, naturalmente, a la ilegalización de la ANL decretada por el gobierno de Vargas a mediados del mes de julio.

26 Tel. N ${ }^{\circ}$ 200, Confidencial, de Bueno a Macedo Soares, Montevideo, 5 de agosto de 1935 (AHI, Vol.3). 
diferentes lugares. Téngase presente que en ese momento y desde el 25 de julio se encontraba sesionando en Moscú el VII Congreso de la Internacional Comunista, cuyas actividades se extenderían hasta el 20 de agosto. El 21 de agosto el Director del Departamento de Prensa e Informaciones de la Cancillería llamaba la atención de sus superiores sobre las noticias de prensa que habían circulado en los primeros días de agosto, y que involucraban a la Legación de la URSS en el Uruguay. "La posición geográfica de Porto Alegre y su proximidad con nuestro territorio - se señalaba - reviste de importancia a esa información que tiene que resultar útil a la policía uruguaya, sugiriendo al Señor Director la conveniencia de hacer la notificación del caso". ${ }^{27}$ Días más tarde, el Subsecretario del Ministerio de Relaciones Exteriores de Uruguay, solicitó al Embajador brasileño informaciones confidenciales sobre los hechos de Porto Alegre. Al comunicar dicha solicitud, el Embajador Bueno agregaba que el gobierno uruguayo estaba "disposto a agir contra o possivel orgão central, o Representante diplomatico dos Soviets, bem contra os agitadores brasileiros".

Si tomamos como cierta esa expresión de intenciones, debemos concluir que la decisión de interrumpir las relaciones con la URSS, adoptada por el gobierno uruguayo en diciembre de 1935, ya venía siendo analizada, por lo menos, desde el mes de agosto de ese año.

Una temprana coordinación antisubversiva. El día 8 de noviembre el Embajador Bueno pedía a Itamaraty avisar al Ministro de Justicia y al Jefe de Policía del Distrito Federal que Luis Carlos Prestes, "conhecido agitador comunista", había sido visto el día 2 de ese mes en la ciudad de Livramento, oculto bajo el nombre de Roberto Castro. Tres días más tarde Bueno telegrafiaba que nuevas informaciones señalaban "que Prestes está realmente no Brasil, aguardando o inicio de um movimento revolucionario de carácter communista, cuja direcção vai asumir entre 14 e 16 do corrente. ${ }^{28}$

A pesar de la situación presuntamente pre-revolucionaria en su país - o quizás, precisamente, debido a ella - Bueno decidió

27 Nota del Director del Departamento de Prensa e Informaciones del Ministerio de Relaciones Exteriores al Director General de dicho Ministerio, Luis Guillot, Montevideo, 21 de agosto de 1935 (Archivo Histórico-Diplomático del Ministerio de Relaciones Exteriores de Uruguay, Fondo Ministerio de Relaciones Exteriores, serie "Comunismo. Actividades en América", Caja 1, Carpeta 2: "Año 1935. Actividades del Comunismo. Ruptura de relaciones con la URSS. Antecedentes" (en adelante: AMREU, FMRE, Comunismo, C1, Carp. 2).

28 Tel. Confidenciales N ${ }^{\circ}$ 260, 260 y 261, de Bueno a Macedo Soares, Montevideo, 8, 9 y 11 de noviembre de 1935 (AHI, Vol. 3). 
partir hacia Brasil de vacaciones; informó que se embarcaría el 23 de noviembre, regresando a Montevideo el 16 de diciembre. ${ }^{29}$

¿Había dejado de creer en la "amenaza" comunista? Obviamente, no. Cuatro días más tarde envió a Macedo Soares una Nota Reservada extremadamente interesante. En ella describía cómo había actuado para enfrentar esta situación pre-revolucionaria, comenzando por un párrafo en el que hacía profesión de fe anticomunista y adelantaba los fundamentos de una coordinación antisubversiva supranacional "Como me competia, nao sómente no meu carácter de funcionario, mas tambem de adversario do comunismo, tomei logo as providencias necesarias junto as autoridades uruguayas, no sentido de pôl-as de sobre-aviso sobre os manejos de Prestes, suas passagens pela fronteira e suas intençoes subversivas. Hoje em dia, todos os Governos estao interesados na luta contra o comunismo e, se os seus adeptos se propôem a formar uma organizaçao internacional, é logico que lhes offereçamos combate, con as mesmas armas e dentro dos seus propios planos, com o intuito de desbaratal-os logo de inicio". ${ }^{30}$

Bueno informó que había mantenido una reunión con el Presidente de la República, con el Ministro de Relaciones Exteriores y con el General Gomeza, Jefe del Estado Mayor del Ejército, "ficando todos prevenidos dos perigos que ameaçam a orden social no Brasil, de molde a poderem agir, em sincronía com qualquer desejo que se lhes manifeste, no momento oportuno", agregando que contaba con el leal apoyo del gobierno uruguayo "para as medidas que quizer, na repressao ao comunismo", estando ahora el Presidente Terra "convencido de que nao se trata de pura fantasia, mas de realidade perigosa para a sua propria conservaçao no Poder". El General Gomeza le había informado que la Legación soviética en Montevideo había recibido recientemente cien mil dólares para la propaganda en América del Sur, siendo cuarenta mil para el Brasil y Argentina, cuarenta mil para Chile y Uruguay y veinte mil más para reforzar los recursos en cualquiera de estos países. ${ }^{31}$ El Embajador brasileño, a su vez, había pedido al militar

29 Tel. N 263 de Bueno a Macedo Soares, Montevideo, 14 de noviembre de 1935 (AHI, Vol. 3).

30 Bueno a Macedo Soares, Nota Reservada $N^{\circ}$ 307, Montevideo, 18 de noviembre de 1935 (AHI, Oficios Montevideo-Río, 1935; en adelante: AHI, Vol. 5).

31 ¿De dónde provenía esta información? Nada dice al respecto el Embajador Bueno en la nota que venimos comentando. El informe elaborado por la Dirección de Investigaciones de la Policía de Montevideo sobre las cuentas bancarias del Ministro Minkin y de la Iuyamtorg, que veremos más adelante, si bien da cuenta de importantes fondos recibidos por la Legación soviética, en ningún momento habla de que el destino de ese dinero fuese el que el General Gomeza refirió en la reunión. 
uruguayo que vigilasen las actividades de la Iuyamtorg, pues le constaba que era esa corporación soviética la que actuaba a la sombra de sus ocupaciones comerciales. Iba más allá el Embajador brasileño, adivinando las intenciones y el pensamiento de los representantes diplomáticos y comerciales soviéticos: "O Ministro da U.R.S.S. procura ocultar as suas actividades no meio intellectual, porque sabe que qualquer manifestaçao que fôr por ella alimentada, tanto aquí, como em paizes frontieriços, com preferencia no Brasil, será logo reprimida pelo Governo oriental, que o despedirá sem mercê. Essa será attitude do Presidente Terra, que me disse, caso haja provas de cumplicidade da Legaçao sovietica nas tramas subversivas que ameaçam a tranquillidade de familia brasileira, a represen-da U.R.S.S. será inmediatamente convidada a retirarse do paiz e rôtas as relaçoes diplomaticas. Creio, porém, que o Señor Minkine, que gosta da vida diplomatica, onde se sente bem entre gente educada e fina, prefere manter-se á margen das agitaçoes e deixar á Yumtorg o trabalho de dissoluçao e de proselitismo. De facto, tanto a Yumtorg como a Legaçao sovietica, sao organos do Governo de Moscú, dirigidos pelas inspiraçoes e ordens da Terceira Internacinal e obedientes ás suas directrices". Luego de este párrafo - que no sabemos si estaba meramente dirigido a informar a Macedo Soares o había sido parte de su planteo ante Gomeza - el Embajador señalaba que había combinado con Espalter y con Gomeza para que, con el pretexto de reprimir el contrabando, se estableciera una estrecha vigilancia en la frontera, habiéndole entregado a ambos fotografías de Prestes, así como detalles de sus señas y características para facilitar su identificación en caso de que apareciese en algún punto próximo a la frontera. ${ }^{32}$

El 23 de noviembre Bueno se embarcó para Río de Janeiro. Ese mismo día estallaba el primero de los tres levantamientos revolucionarios de noviembre de 1935. Con ellos se inicia la etapa final de nuestra historia y el período más complejo de esta crisis diplomática. El protagonismo que adquiriría Lucillo Bueno en este momento nos inclina a pensar que su viaje a Brasil no estuvo determinado únicamente por razones familiares.

Los sucesos revolucionarios culminaron el día 27, con la derrota de los sublevados, a la que siguió una muy fuerte represión a las fuerzas de izquierda y la oposición en general.

32 Bueno a Macedo Soares, Nota Reservada No 307, cit. 
Entre la derrota de los revolucionarios y la ruptura de relaciones diplomáticas con la URSS decidida por el gobierno de Terra, transcurrió exactamente un mes. Reconstruir el día a día de la diplomacia de ambos países en ese mes cargado de tensiones resulta revelador de las intenciones de ambos gobiernos, así como de las estrategias seguidas y de los instrumentos utilizados. Lamentablemente, el carácter acotado de este trabajo nos impide hacerlo. Confiamos en que la síntesis que ofrecemos a continuación logre transmitir los elementos esenciales de aquella coyuntura.

\section{Los levantamientos de noviembre y la "diplomacia del anticomunismo"}

Las "comprobaciones" del Embajador Bueno. Cuando las noticias de los levantamientos revolucionarios en Brasil comenzaron a llegar a Montevideo, los cables mencionaban a la capital uruguaya como lugar de apoyo logístico de los revolucionarios. El día 26, cuando la situación aún no estaba totalmente controlada, el Embajador uruguayo en Brasil, Juan Carlos Blanco, se entrevistó con el canciller José de Macedo Soares, telegrafiando luego al Ministro Espalter que el Canciller brasileño le había dicho "muy cordialmente pero con firmeza" que su gobierno creía que el grave movimiento comunista había sido preparado y dirigido desde Montevideo por la Iuyamtorg y la Legación Rusa "según comprobaciones [del] Embajador Bueno quien dice conocer toda la procedencia del dinero empleado". Y agregaba: "Creo conveniente efectuar averiguaciones ahí y hacer aquí por mi intermedio alguna declaración al respecto destinada a tranquilizar [a] este Gobierno que nos ha dado pruebas [de] amistad". 33

En el escueto mensaje estaban contenidos los elementos esenciales del conflicto y de lo que sería la postura uruguaya: preocupación por la "firmeza" con que Brasil planteaba la existencia de la conexión soviética en Uruguay; protagonismo del Embajador Bueno en su condición de "acusador"; necesidad de investigar para confirmar aquellas presunciones $y$, ante todo, urgencia de actuar de modo de "tranquilizar" al gobierno brasileño, cuya amistad era tan importante para Uruguay.

Ese mismo día, la Embajada brasileña en Montevideo recibía un telegrama de Macedo Soares en el que éste informaba que los

33 Tel. N 4671, Cifrado, de Blanco a Espalter, Río, 25 de noviembre de 1935 (AMREU, Fondo Ministerio de Relaciones Exteriores, Serie BRASIL, Caja 4, Carpeta 1: "Año 1935. Brasil. Actividades Subversivas"; en adelante, citada como: AMREU, FMRE, Brasil, C4, Carp. 1). 
movimientos armados de carácter bolchevique surgidos en algunos puntos de Brasil obedecían a inspiraciones del Gobierno de Moscú, que los dirigía y apoyaba por intermedio de la Iuyamtorg; agregando: "julgamos de alta conveniencia obter do Governo uruguayo a dissoluçao dessa organizaçao sovietica, que, além de procurar subvertir a orden publica no Brasil, ameaça a tranquillidade do Continente sul-americano" ${ }^{34}$

Espalter de inmediato instruyó a Juan C. Blanco para que dijese a Macedo Soares y al Presidente Vargas que Uruguay procedería a investigar los hechos denunciados, y que el Presidente Terra manifestaba que, en caso de que dichos hechos fuesen considerados "probables" se tomarían las medidas del caso, que podrían llegar hasta la ruptura con la URSS. ${ }^{35}$ Pero Espalter también pidió datos concretos a Itamaraty, tanto por intermedio de la Embajada brasileña en Montevideo como a través del Embajador Blanco. Como Macedo Soares esgrimió como tal, ante este último, el texto del discurso pronunciado ante el VII Congreso de la Internacional Comunista, por el "delegado holandés" Van Mine, el Canciller uruguayo indicó a Blanco que le solicitase el texto de dicho discurso. Blanco cablegrafió el párrafo sustancial en el que Van Mine habría dicho que la Alianza Nacional Libertadora había sido creada bajo la orientación secreta pero directa del partido comunista brasileño y siguiendo las "instrucciones confidenciales recibidas de la Legación Soviética en Montevideo". ${ }^{36}$ Pero Espalter quería el texto completo, y Blanco se lo envió. ${ }^{37}$

34 Tel. N ${ }^{\circ}$ 148-31510, Confidencial, de Macedo Soares a Embajada en Montevideo, Río, 26 de noviembre de 1935 (AHI, Vol. 6).

35 Tel. M.2509, Cifrado, de Espalter a. Blanco, Montevideo, 26 de noviembre de 1935 (AMREU, FMRE, Comunismo, C1, Carp. 2).

36 Tel. N ${ }^{\circ}$ L.4678, Cifrado, de Blanco a Espalter, Río, 29 de noviembre de 1935 (AMREU, FMRE, Brasil, Caja 4, Carp. 1).

37 El 29 de noviembre Juan Carlos Blanco telegrafiaba anunciando el envío del texto completo del discurso - que le había sido entregado personalmente por Macedo Soares junto a otros documentos que enviaba por intermedio del comisario del vapor Asturias - y transcribiendo el párrafo del discurso del "delegado holandés" en el que se aludía a Uruguay: "... Debo exponer a todos los camaradas que se interesan por el desenvolvimiento y expansión del comunismo en América meridional que en el Brasil ya existe una amplia y bien organizada asociación llamada Alianza Nacional Libertadora y de la cual ya participan gran número de oficiales y soldados del ejército y de la marina Brasileras. Esa alianza fue creada bajo la orientación secreta del partido comunista Brasilero según las instrucciones confidenciales recibidas de la Legación Soviética de Montevideo" (telegrama L. 4678 de Juan Carlos Blanco a Espalter. Río de Janeiro, 29 de noviembre de 1935) (AMREU, Fondo Legaciones y Embajadas, Embajada del Uruguay en Brasil, Caja 38, Telegramas. 1935. En adelante: AMREU, FLE, Emb. Brasil, C38). En dos oportunidades Blanco alude al envío de 
El 27 de noviembre, una vez que se tuvo la noticia oficial de que los sublevados habían sido derrotados, el Embajador uruguayo visitó a al Presidente Vargas y a Macedo Soares, transmitiéndoles las felicitaciones del Presidente Terra por haber sofocado la rebelión. El Presidente Vargas le dijo enviaría al gobierno uruguayo los resultados de las investigaciones que se estaban realizando, como elementos de juicio. En su entrevistaron el Canciller, "en forma extremadamente cordial", éste le había hecho entrega de "algunos documentos probatorios" del carácter comunista de la rebelión (obsérvese que no se habla de que fuesen probatorios de la implicancia de la Legación soviética). El último párrafo de su telegrama era tranquilizador: "Creo que una perturbación en las relaciones entre ambos países se encuentra absolutamente alejada" gracias a la "la rapidez con que hemos actuado y las medidas adoptadas por el Sr. Presidente de la República y por Vd.". No obstante ello, Blanco entendió, seguramente, que había aspectos de esta problemática que debían conversarse personalmente, por lo que pidió autorización para viajar de inmediato a Uruguay, rogando a Espalter que no se tomara ninguna resolución definitiva sobre el tema hasta su arribo. Antes de partir, en una nueva entrevista con el canciller brasileño, Blanco preguntó a Macedo Soares cuál era su "pensamiento íntimo" en torno a este tema, a lo que éste respondió: "Yo, poniéndome en el lugar de Uds. aprovecharía esta magnífica oportunidad, para librarme de los Soviets".

En el despacho en el que daba cuenta de esta reveladora conversación, el Embajador uruguayo hacía una valoración de la situación, señalando que, de las primeras impresiones que había recogido "en los más indicados medios políticos y militares de esta capital", se desprendían las siguientes conclusiones: "1.- que la rebelión tuvo un carácter comunista; 2.- que parece probable que el dinero o parte del dinero destinado a la propaganda y a la sublevación, haya sido traído del Uruguay, a través de la frontera, por agentes soviéticos. Este Gobierno ejerce un contralor especial

documentos que le fueron entregados por Macedo Soares, cuyo detalle no incluye, aunque sí menciona el envío del texto completo del discurso de Van Mine. En el AMREU encontramos los documentos enviados por Blanco: se trata de textos mecanografiados y mimeografiados, en idioma portugués, que tienen el sello de la Embajada de Uruguay en Brasil; adosado a uno de ellos se encuentra la tarjeta de visita del Canciller Macedo Soares, con la anotación manuscrita: "Com as suas cordiaes saudaçoes. 24/XI/35". No está entre ellos el discurso de Van Mine. El texto de dicho discurso que se encuentra en el AMREU fue enviado, como veremos, por la Legación del Uruguay en Moscú. 
y policial sobre todo giro bancario de cierta importancia proveniente del Uruguay y no existen rastros en los bancos de giros destinados a los comunistas en Brasil; 3.- No se tiene la prueba, de la intervención en estos sucesos de la Legación Soviética de Montevideo; 4.- La única alusión al Uruguay que se encuentra en las actas conocidas hasta ahora del séptimo Congreso Comunista Internacional de Moscow [sic], es la relativa a las palabras pronunciadas por el delegado Holandés Van Mine, en ese Congreso, y que consta en uno de los documentos que envío".

Pero tanto o más importantes que estas conclusiones, son las que el Embajador uruguayo sacó de la entrevista que mantuvo con el Presidente Vargas "el día de la rebelión" (27 de noviembre, día de la insurrección en Río de Janeiro). Según Blanco, "el Doctor Vargas desea que el Gobierno del Uruguay tome medidas contra las actividades soviéticas en su territorio, pero [...] cree que esas medidas deben adoptarse lentamente, en cierto plazo de tiempo relativamente largo, con objeto de evitar la creencia de que en Sud América se le teme excesivamente a Moscow [sic], a punto de concertarse los países para una acción violenta. Puede parecer este criterio contradictorio con las medidas solicitadas por el Ministro de Relaciones Exteriores Doctor Macedo Soares en las conferencias que mantuve con él - sin embargo, el fondo es el mismo, lo que busca el Gobierno del Brasil es que el Gobierno del Uruguay verifique una investigación e impida en la forma que crea más conveniente que desde Montevideo, los agentes del Soviet, puedan fomentar disturbios en el Brasil". Y a continuación incluyó un párrafo revelador de las presiones ejercidas por el gobierno brasileño: "El Ministro Macedo Soares que es un hombre muy tranquilo y amable, llegó a decirme que el Brasil se vería obligado a suspender todo tráfico comercial y de personas con el Uruguay y a cerrar las fronteras para defenderse de un peligro que, imaginario o no, el Gobierno del Brasil cree que existe". ${ }^{\prime 3}$

Con pruebas o sin ellas, el gobierno brasileño estaba convencido de que el peligro existía. ¿Valía la pena seguir investigando sobre la verdad de los hechos? A pesar de ello, el Canciller uruguayo parecía empeñado en obtener más información, pero, quizás para su sorpresa, su colega brasileño en vez de proporcionarle pruebas se las solicitó: el 30 de noviembre Macedo Soares convocó a Blanco

38 Nota $N^{\circ}$ 377/935 de Blanco a Espalter, Río, 29 de noviembre de 1935. (AMREU, FMRE, Brasil, C4, Carp. 1) 
a su despacho y le informó que esa misma mañana había recibido un telegrama del Embajador de Brasil en Washington, Osvaldo Aranha, que le leyó, en el que le transmitía la opinión del Presidente F. D. Roosevelt sobre la rebelión brasileña y el comunismo. Con indisimulado orgullo Blanco informó: "La declaración del Presidente Roosevelt es idéntica a la declaración del presidente Doctor Gabriel Terra que yo comuniqué al Dr. Vargas y al Ministro Macedo Soares el mismo día del martes 27 de Noviembre. El Presidente de Estados Unidos dice que si encuentra pruebas de complicidad de la Embajada de los Soviets o si encuentra giros anormales de la Embajada o de sociedades comerciales soviéticas ya al Uruguay o al Brasil o a cualquier otro país de la América, declarará terminadas las relaciones oficiales de los Estados Unidos con el gobierno de los Soviets". Luego de darle a conocer el cable, Macedo Soares había pedido a Blanco tres cosas: que enviara al gobierno uruguayo lo más rápidamente posible esta información; que transmitiera la solicitud oficial de "cualquier prueba bancaria o no de complicidad de la Legación Soviética en Montevideo o de Sociedades Comerciales Soviéticas (Yuyamtorg) u otras, pues tiene el gobierno del Brasil el más alto interés en ofrecer pruebas o semi-pruebas al gobierno Americano para decidirlo a romper con los Soviets"; y en tercer lugar le había dicho que "no como ministro, sino como camarada (textual), compañero y amigo" le pedía transmitiese al canciller uruguayo "su opinión de que, estos sangrientos y terribles sucesos en el Brasil (textual) son un buen pretexto para librar a América de la propaganda oficializada soviética". ${ }^{39}$

Nuevamente el Canciller brasileño sugería a Uruguay que se "liberase" de los agentes soviéticos y de su propaganda. Pero su insistencia no era la única herramienta de presión sobre Uruguay; un papel destacado le cupo a la cierta prensa brasileña que, con titulares tipo catástrofe, propagaba versiones alarmistas y de alto contenido denigratorio hacia las autoridades uruguayas que permitían la acción disolvente del comunismo. Un ejemplo de ello tenemos en los recortes de los diarios A Rua y Diario Carioca, del 4 de diciembre de 1935, enviados a Montevideo por el Encargado de Negocios de Uruguay, en los que se insistía en la influencia directa y principal de la Iuyamtorg en los sangrientos sucesos. Saavedra

39 Carta manuscrita, Confidencial, de Blanco a Espalter, Río, 30 de noviembre de 1935. El subrayado y las palabras entre paréntesis, están en el original (AMREU, FMRE, Comunismo, C1, Carp. 2). 
Barroso advertía a Espalter que Diario Carioca era dirigido por el Senador José Eduardo de Macedo Soares, hermano del canciller, y que "tanto en su orientación como en sus informaciones se inspira en Itamaraty". ${ }^{40}$

¿Qué hacer ante esta presión? El gobierno uruguayo continuaba navegando en aguas revueltas, inclinándose a dos bandas: por un lado, adoptaba medidas destinadas a "tranquilizar" al gobierno brasileño y, por otro, seguía procurando informaciones fidedignas. Entre las primeras estuvo el envío de una instrucción a las Embajadas en Brasil y Argentina ordenando comunicar a los respectivos Consulados la prohibición de visar pasaportes con destino al Uruguay, para "toda persona sindicada como extremista". ${ }^{41}$ Entre las segundas, podemos señalar la solicitud a la Legación en Moscú para que confirmase si en el VII Congreso de la Internacional Comunista, "un delegado Holandés o cualquier otro, como se la ha afirmado al Gobierno del Brasil", manifestó que la Legación Soviética en Montevideo "era agente directo o indirecto de manejos comunistas en Sudamérica". ${ }^{42}$ Un pedido similar hizo Espalter a la Embajada en Santiago de Chile, pidiendo cualquier dato en relación con afirmaciones de la prensa chilena que hablaban de que todas las agitaciones comunistas tenían su centro en Montevideo. ${ }^{43}$ A medio camino entre la indagatoria y las medidas tranquilizadoras puede ubicarse el pedido formulado al Ministro de Uruguay en Washington, José Richling, para que manifestara al Secretario de Estado que el gobierno uruguayo deseaba conocer el criterio del gobierno de Estados Unidos "frente a los hechos revolucionarios acaecidos en Brasil, y al indudable incremento comunista sudamericano". También debía decirle que el gobierno uruguayo estaba dispuesto a entregar los pasaportes al Ministro soviético "si confirmara o hubiere presunciones" de grave intervención de la Legación soviética en Montevideo en el movimiento revolucionario de Brasil, agregando que Uruguay "estaría dispuesto ejercer acción colectiva, con criterio países sudamericanos frente a

40 Nota N ${ }^{\circ} 381$ de Saavedra Barroso a Espalter, Río, 4 de diciembre de 1935 (ibid.).

41 Tel. Cifrado, Urgente, Recomendado, de Espalter a Embajada en Río; y Tel. cifrado M.2011 de Espalter a Emb. en Buenos Aires, Montevideo, 5 de diciembre de 1935 (ibid). No sabemos si dicho telegrama fue circulado a otras Embajadas o Legaciones en América.

42 Tel. M.8610, cifrado, de Espalter a Masanés, Montevideo, 9 de diciembre de 1935 (Ibid).

43 Tel. M.3440, Cifrado, de Espalter a Embajada en Santiago de Chile, Montevideo, 18 de diciembre de 1935 (ibid). 
estos hechos". Richling informó sobre el resultado de sus entrevistas con el Secretario Cordell Hull y con el Subsecretario Sumner Welles: Estados Unidos estaba deseoso de conocer mayores detalles pero, en relación con una posible acción colectiva que pudiera traducirse en una ruptura diplomática con la URSS, Hull dudaba de que Estados Unidos pudiese solidarizarse con ella en razón de que para proceder en esa materia debía guiarse por lo estipulado en el convenio de reanudación de relaciones diplomáticas con Rusia que, mientras fuese cumplido, Estados Unidos también debía respetar. ${ }^{44}$

Desechado el posible respaldo de Estados Unidos y el sistema panamericano para una eventual ruptura con la URSS, Uruguay debería hacer frente en soledad a dicha medida. Esta, por lo tanto, debería estar bien fundamentada. Pero la respuesta que llegó desde Moscú estuvo lejos de ser una confirmación. El Encargado de Negocios en la capital soviética, Carlos Masanés, informó a Espalter que el delegado Van Mine no era holandés sino chino, y señaló que en su discurso - cuyo texto completo, traducido al español, envió no había ninguna referencia a Uruguay o a la Legación soviética en Montevideo. Masanés razonaba - en forma bastante convincente "que ningún delegado se hubiera permitido hacer la más leve alusión a los representantes diplomáticos, consulares o comerciales soviéticos en el exterior", ya que ello iba en contra de las directivas del gobierno de aquel país, que quería mostrar hacia el exterior la independencia de la Internacional Comunista de las decisiones del gobierno soviético. "Además - decía Masanés - no sería necesaria ni eficaz la intervención de los funcionarios oficiales de la URSS, ya que el Kommintern TIENE DELEGADOS OFICIALES EN TODOS LOS PAÍSES DONDE EXISTEN NÚCLEOS IMPORTANTES DE COMUNISTAS!". Y agregaba: "Yo creo, Señor Ministro, que la Legación Soviética en Montevideo no ha intervenido de una manera 'directa' en los desórdenes del Brasil. Puede ser que su rol se haya limitado, 'indirectamente' a facilitar las comunicaciones del 'Kommintern' con su delegado en el Brasil, utilizando la clave telegráfica o el correo diplomático"; y concluía: "el NOMBRE DE

44 Nota $\mathrm{N}^{\circ}$ 987, Confidencial, de Richling a Espalter, Washington, 10 de diciembre de 1935, en la que se transcribían las instrucciones enviadas por el Canciller (ibid). Al informar sobre la gestión que había realizado Brasil ante Estados Unidos, el Embajador Juan Carlos Blanco había aconsejado a Espalter: "Inútil decirle que creo nos corresponde conocer con toda precisión la actitud de los Estados Unidos - el ideal sería una decisión conjunta o mejor dicho simultánea" [el subrayado está en el original] (Carta de Blanco a Espalter, Río, 30 de noviembre de 1935, cit. [AMREU, FMR, Brasil, C4, Carp.1]). 
NUESTRO PAÍS NO HA SIDO PRONUNCIADO NI UNA SOLA VEZ en los discursos de los delegados publicados en la prensa soviética y en las ediciones francesa e inglesa del 'Boletín de la Internacional Comunista'" ${ }^{45}$

¿Qué había de cierto entonces? ¿Cuál era la verdad en torno al discurso de Van Mine? ¿Itamaraty había accedido a una versión más completa del texto o, simplemente, los servicios de inteligencia brasileños habían inventado el párrafo para convencer de una vez por todas al gobierno uruguayo de que tenía que acabar con su tolerancia ante las actividades comunistas y soviéticas? Es probable que el Canciller uruguayo se estuviese haciendo alguna de estas preguntas. Las investigaciones dispuestas no habían avanzado demasiado. La respuesta de la Embajada en Chile no aportó datos precisos: el Embajador en Santiago creía que las noticias publicadas unos días atrás por la prensa de esa capital eran exageradas, y en aquel país no se les había dado mayor importancia. ${ }^{46} \mathrm{El}$ informe solicitado a la División de Investigaciones de la Policía de Montevideo tampoco resultó concluyente. ${ }^{47}$

A la vista de estos antecedentes parece claro que hasta ese momento los elementos de juicio en los que la Cancillería brasileña había basado sus actuaciones eran las afirmaciones del Embajador Bueno. La desconfianza sobre su actuación en aquella coyuntura fue expresada con toda claridad por el Encargado de Negocios de Uruguay en Río, quien lo consideró "uno de los principales instigadores" de las versiones que insistían en que las relaciones de Uruguay con la URSS eran un peligro para toda América. Saavedra Barroso relató a Espalter una anécdota más que sugestiva: el 17 de diciembre, siguiendo las instrucciones recibidas de Montevideo, se

45 Nota 181/935, de Masanés a Espalter, Moscú, 11 de diciembre de 1935. El subrayado, las mayúsculas y el signo de admiración, están en el original.

46 Tel. L.3990, de Embajada en Chile a Espalter, 19 de diciembre de 1935 (AMREU, FMRE, Comunismo, C1, Carp. 2).

47 Dicha División elevó un informe sobre las indagatorias realizadas en relación con las cuentas bancarias a nombre del Ministro soviético, Alexander Minkin, y los movimientos de las mismas. La información proporcionada en forma estrictamente confidencial - en Uruguay regía el secreto bancario por lo que dar información sin una orden judicial era violatorio de las disposiciones legales - por los gerentes de dos instituciones bancarias de plaza (el Banco Real de Canadá y el Banco Francés e Italiano) no aportaba pruebas concluyentes. Minkin tenía varias cuentas bancarias, donde recibía giros desde Nueva York (de la Norkomfin) y desde Buenos Aires (girados por la Iuyamtorg), y sobre las cuales emitía cheques al portador, por lo que era muy difícil establecer el destino de los fondos. (Informe "Confidencial" $\mathrm{N}^{\mathrm{o}} 23$, del Jefe de la División Investigaciones, José P. Casas, al Jefe de de la Policía de Montevideo, Marcelino Elgue, Montevideo, 24 de diciembre de 1935 (ibid). 
había entrevistado con Macedo Soares, entregándole un telegrama de Espalter en el que éste reiteraba el interés del gobierno uruguayo por recibir datos concretos sobre la participación soviética en los levantamientos, y manifestaba la esperanza de que el Embajador Bueno a su regreso a Montevideo pudiese realizar "algún aporte provechoso en ese sentido". La respuesta de Macedo Soares había sido vaga: aprovecharía el regreso de su Embajador, que partía ese mismo día, "para dictarle algunas instrucciones que crea convenientes para la defensa en común" frente a las "ideas extremistas". Esa noche, en la despedida ofrecida al Embajador Bueno, éste había dicho a Saavedra Barroso: "hoy estuve con el Ministro a despedirme y me mostró el telegrama del doctor Espalter, pidiéndome mi opinión. Después de leerlo le dije: muchas palabras pero pocos hechos a lo que me contestó: opino lo mismo. Y esto que se lo digo a Ud. Se lo diré al Señor Ministro [Espalter] cuando llegue, agregándome que había llegado el momento, dada la extrema gravedad de los sucesos, que el Uruguay definiera claramente sus posiciones, o la amistad con el Brasil o con los soviets. Este es continuaba Saavedra Barroso - más o menos el estado de ánimo, no diré del Gobierno del Brasil, pero sí de su representante en nuestro país que con sus informaciones alarmistas y a mi modo de ver exageradas, podrían llegar a influir a entibiar las excelentes y amistosas relaciones que hasta ahora hemos cultivado con el Brasil". ${ }^{48}$

La "fórmula" para la ruptura. Mientras la prensa brasileña continuaba sus ataques a Uruguay, el Embajador brasileño regresó a Montevideo el 21 de diciembre, retomando su militancia anticomunista, que ahora lindaban con la conspiración. A su regreso a Montevideo informó a Macedo Soares que había encontrado ambiente favorable para hallar una fórmula que facilitase el alejamiento de los agentes oficiales soviéticos del Uruguay, pero que precisaba datos de la Policía brasileña concretamente, solicitaba que se obtuviesen de la Policía del Distrito Federal declaraciones de detenidos - que sirviesen al gobierno uruguayo como pretexto para ese fin. Se había entrevistado con el Jefe de Policía y con el Jefe del Estado Mayor del Ejército, "ambos francamente favoraveis a exercer influencia junto ao Presidente Terra para esse fim". El 25 de diciembre Bueno hizo una visita de cortesía al Presidente Terra y lo encontró en compañía del Canciller

48 Nota N 395/935 de Saavedra Barroso a Espalter, Río, 18 de diciembre de 1935 (Ibid). 
Espalter, del Ministro de Defensa, del Jefe del Estado Mayor del Ejército y del Jefe de Policía. Terra abordó el tema del comunismo y pidió a Bueno que le dijese qué deseaba del gobierno uruguayo con referencia a ese tema. "Afectando desinteresse pelo assumpto" relató Bueno a Macedo Soares - disse-lhe que tinha instrucçõoes pessoaes e verbaes do Señor Presidente da Republica para deixar esse delicado assumpto ao criterio da propria soberania Uruguay convencido, porém, de que Sua Excellencia o resolveria de acordo com a amizade tradicional que une os dois paizes, reafirmada pelas visitas presidenciaes de 1934 e de 1935". Terra le solicitó entonces que hiciera un relato de los sucesos revolucionarios, cosa que Bueno hizo, ilustrándolo con los ejemplares de $A$ Manhã del día de la rebelión en Río de Janeiro y del ejemplar del Correio da Manhã del 11 de diciembre. Finalizado el relato, Terra preguntó a los presentes si no era clara la narración de los sucesos de Brasil, si no resultaba evidente la participación del Gobierno de Moscú en la insurrección brasileña y si no creían que la solidaridad americana obligaba a Uruguay a romper relaciones con el gobierno ruso, alejando a la Legación soviética y suspendiendo la personería jurídica a la Iuyamtorg. El Ministro Espalter formuló, al parecer, algunas observaciones, pero el Jefe de Policía mostró el resultado de las investigaciones policiales, de las que - según dijo - resultaba evidente que la Legación soviética distribuía cheques al portador y había realizado operaciones de cambio con moneda brasileña en varias oportunidades, en diferentes establecimientos bancarios de Montevideo. ${ }^{49}$ Recapitulando las palabras de los presentes, Terra dijo "que a amizade do Brasil era insubstituible e que o Presidente Vargas lhe merecia o mayor apreço e era digno da admiração de todos os uruguayos e que a palabra do Embaixador brasileiro era suficiente para esclarecer a situação". Afirmó entonces que el Gobierno uruguayo iba a tomar una resolución final sobre el asunto y pidió a Bueno que le enviase una nota narrando, como lo acababa de hacer, el levantamiento comunista y que, basándose en esa nota, rompería relaciones con los soviets y clausuraría la Yuyamtorg.

Bueno agradeció efusivamente dicha declaración y se comprometió a entregar al día siguiente la comunicación solicitada. Al informar estas novedades a Macedo Soares, el Embajador Bueno le solicitaba que pusiera esa grata noticia en conocimiento del

49 Se trataba, obviamente, del Informe elaborado por la División Investigaciones, que ya hemos citado y que estaba fechado el día anterior a dicha reunión. Sin embargo, en el informe no se aludía a compras de moneda brasileña. 
Presidente Vargas, y se congratulaba por haber llegado, "pela persuassão, a un fim tão almejado, de accordo com as instrucções do nosso Presidente e as instrucções que Vossa Escellencia se dignou de me dar, por accasião da minha partida. Creio haver cumplido o meu dever, obtendo, espontáneamente, do Presidente Terra decisão de tão alta importancia, que demonstra o desejo deste Governo de se manter estreitamente solidario na sua orientação em tudo o que possa referir-se ao Brasil" ${ }^{50}$

La nota de la Embajada de Brasil fue entregada el mismo día 25 de diciembre. El decreto de ruptura de relaciones de Uruguay con la URSS fue firmado el 27 de diciembre y ese mismo día el introductor de embajadores, Fermín de Yéregui, concurrió a la Legación soviética a entregar los pasaportes al Ministro Minkin.

La decisión del gobierno de Terra contó con el apoyo de los órganos de prensa situacionistas y fue duramente criticada por la oposición. El Embajador Lucillo Bueno y Macedo Soares se congratularon mutuamente. ${ }^{51}$ Macedo Soares envió un extenso telegrama de agradecimiento al Canciller Espalter, en el que elogiaba la clarividencia de la política de Uruguay, realzada por un alto concepto de amistad continental, de "solidaridade e defesa commum das livres democracias americanas, as quaes juntam ao zelo da sua soberania internacional o firme proposito de defenderem a civilização christã em que se formaram", y terminaba afirmando que el texto de ese telegrama sería comunicado a todos los gobiernos americanos para que se conservase en las respectivas Cancillerías "o documento de um facto de tão alta significação historica" ${ }^{52}$

A la campaña denigratoria de la prensa sucedió una apoteosis de demostraciones de simpatía hacia el pueblo uruguayo, y el Embajador Juan Carlos Blanco fue objeto de un homenaje multitudinario en Río de Janeiro.

Uruguay debería hacer frente en la Sociedad de las Naciones a la protesta de la URSS. La defensa de la posición uruguaya estuvo a cargo del delegado del país en Ginebra, el Dr. Alberto Guani (futuro Canciller en el período 1938-1943). El gobierno brasileño, deseoso de respaldar la decisión uruguaya, instruyó a sus representaciones

50 Tel. reservado No. 269 y Confidencial $N^{\circ}$ 272, de Bueno a Macedo Soares, Montevideo, 23 y 25 de diciembre de 1935 (AHI, Vol. 3).

51 Telegramas $\mathrm{N}^{\mathrm{o}} 285$ y N $\mathrm{N}^{\mathrm{2}} 286$, de Bueno a Macedo Soares, Montevideo, 27 de diciembre de 1935 (ibid); y Tel. No 159-71700 de Macedo Soares a Bueno, Río, 28 de diciembre de 1935(AHI, Vol. 6).

52 Tel. N $^{\mathrm{o}}$ 158-71500 de Macedo Soares a Bueno, Río, 28de diciembre de 1935 (ibid). 
diplomáticas en toda América para que gestionasen, en sus respectivos países de destino, el apoyo a Uruguay en aquel organismo. ${ }^{53}$

El despacho confidencial enviado por el Embajador Lucillo Bueno el 30 de diciembre es singularmente valioso, por lo que significa en términos de reconocimiento de la forma en que Uruguay adoptó la decisión. En un pasaje de dicha nota, expresió: "O Señor Presidente Gabriel Terra agiu rapida e decisivamente no assumpto, não dando tempo a que os Soviets se apegassem aos seus habituaes subterfugios. Hoje, é un facto a cessação de relaçoes com Russia vermelha. O Uruguay, com isso, quiz dar mais uma prova dos seus sentimentos fraternaes para com o Brasil fiando-se na minha palabra official e baseando-se, apenas, na minha nota de 25 do corrente [...]. Os termos do Decreto de ruptura constituem um acto sem igual na Historia diplomatica. O Governo do Uruguay se mostra solidario com o Brasil, ante a insolita aggressão comunista, tramada pelos orgãos de Moscú e firma, assim, públicamente, um Tratado defensivo com o nosso paiz. O alcance desse acto é de magna transcendencia. Sinto-me feliz por ter podido cumprir o que prometti ao Excellentissimo Señor Presidente da Republica e a Vossa Excellencia e prestado, dest'arte, um serviço tão importante ao nosso paiz, em momentos em que os esforços de todos or brasileiros são para jugular o comunismo". ${ }^{54}$

\section{Conclusiones}

El análisis de la correspondencia diplomática de ambos países durante el año 1935, nos lleva a conclusiones esperadas: existió una fuerte presión del gobierno de Getúlio Vargas para que Uruguay alejase de su territorio a la Legación soviética y a la Iuyamtorg. El gobierno de Terra no podía hipotecar su amistad con el país vecino, entre otras cosas porque, como quedó evidenciado en enero, su propia seguridad interna dependía de la buena voluntad de las autoridades brasileñas; por lo que la decisión adoptada fue una lógica consecuencia.

Pero estas conclusiones no son las únicas; las hay también menos previsibles. Desde bastante antes de los levantamientos de noviembre, el canciller brasileño Macedo Soares ya tenía planteado como objetivo eliminar la presencia soviética en Uruguay

53 Tel. No 7-71100 de Macedo Soares a Bueno, Río, 18 de enero de 1936 (ibid).

54 Nota Confidencial No 325 de Bueno a Macedo Soares, Montevideo, 30 de diciembre de 1935 (AHI, Vol. 5). 
y el Embajador Lucillo Bueno había recibido instrucciones en ese sentido. Durante la crisis de finales de 1935 quedó en evidencia que Macedo Soares quería, asimismo, lograr que Estados Unidos rompiera sus relaciones con los soviets. El Embajador Bueno creía que Terra no estaba convencido de la existencia del "peligro" comunista, por lo que el diplomático se puso en contacto (¿conspiró?) con el Jefe de Policía de Montevideo y el Jefe del Estado Mayor del Ejército, para que lo apoyaran en la tarea de convencer a Terra. En el momento de adoptar la decisión, el Presidente de Uruguay y su Canciller seguramente estaban conscientes de que no existían pruebas contundentes que implicaran a la Legación soviética en el apoyo a los levantamientos comunistas, pero entendieron que, si querían conservar la amistad de Brasil, no podían hacer otra cosa que ceder a sus deseos. Por ello el decreto de interrupción de relaciones fue tan cuidadosamente redactado, dejando constancia de que la decisión se tomaba a partir de las afirmaciones hechas por el Embajador de Brasil, y del "convencimiento" del gobierno del país vecino.

La "diplomacia del anticomunismo", que desde principios de la década del treinta había concentrado sus críticas en la permisividad de Uruguay ante las actividades comunistas, había obtenido, finalmente, un resonante triunfo. 